\section{Michigan Technological \\ 18 8 5 University}

Michigan Technological University Digital Commons @ Michigan Tech

Global Conference of the Youth Environmental

Alliance in Higher Education

Apr 21st, 1:45 PM - 1:54 PM

\title{
Session 1E Oceanic Manta Ray (Mobula birstrosis): A Conservation Strategy
}

Cameron Marshall

University of Derby

Follow this and additional works at: https://digitalcommons.mtu.edu/yeah-conference

\section{Recommended Citation}

Marshall, Cameron, "Session 1E Oceanic Manta Ray (Mobula birstrosis): A Conservation Strategy" (2021). Global Conference of the Youth Environmental Alliance in Higher Education. 24.

https://doi.org/10.37099/mtu.dc.yeah-conference/april2021/all-events/24 


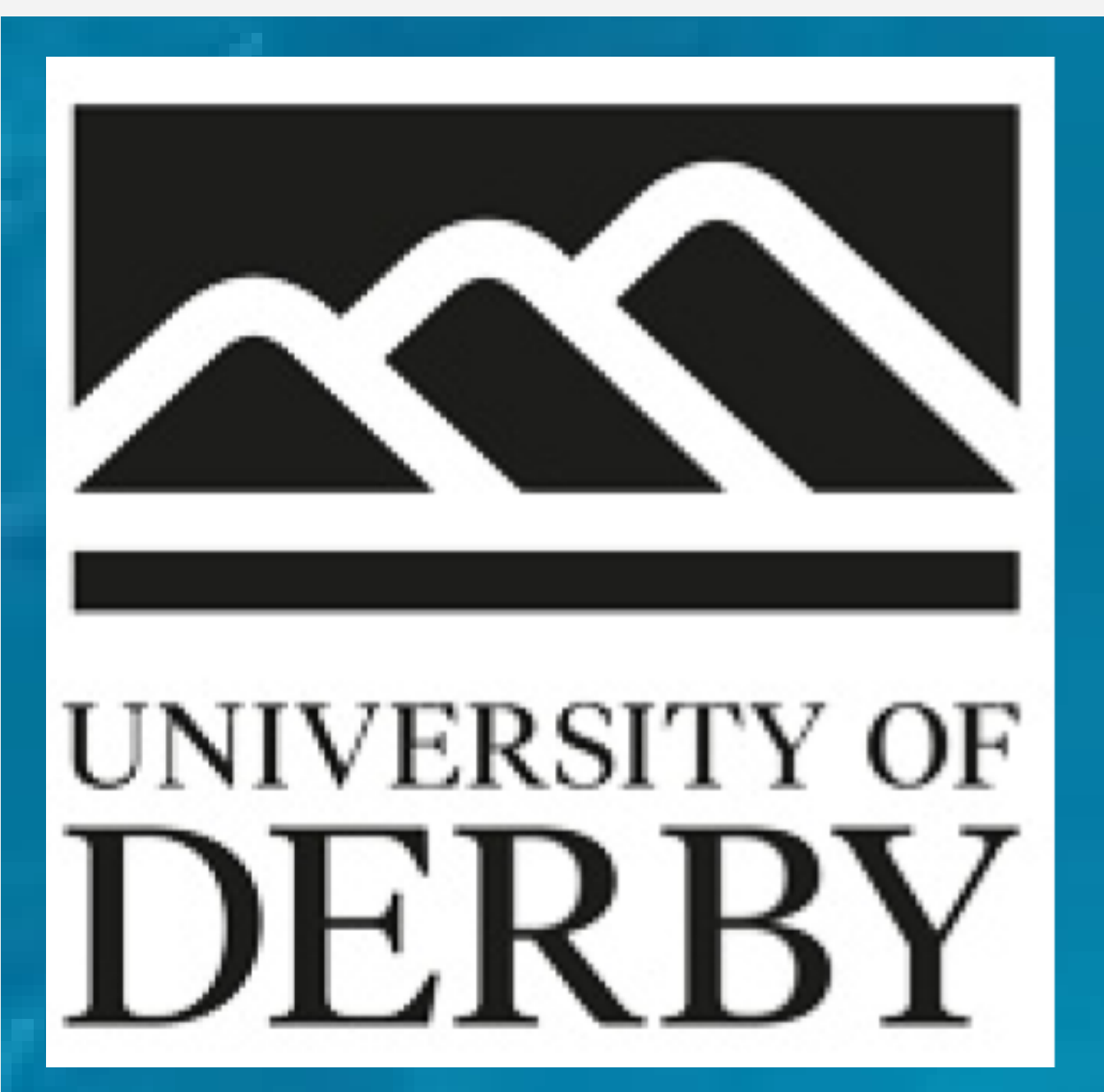

\section{Oceanic Manta Ray (Mobula birstrosis): A Conservation Strategy}

Contact: 100444820@unimail.derby.ac.uk

\section{Introduction}

The Oceanic Manta Ray (Mobula birstrosis) is the largest species of Ray on the planet (Graham et al., 2012). The species migrates circum-globally (Marshall et al., 2020). Figure 1 , below shows the species size and (known) geographic range.

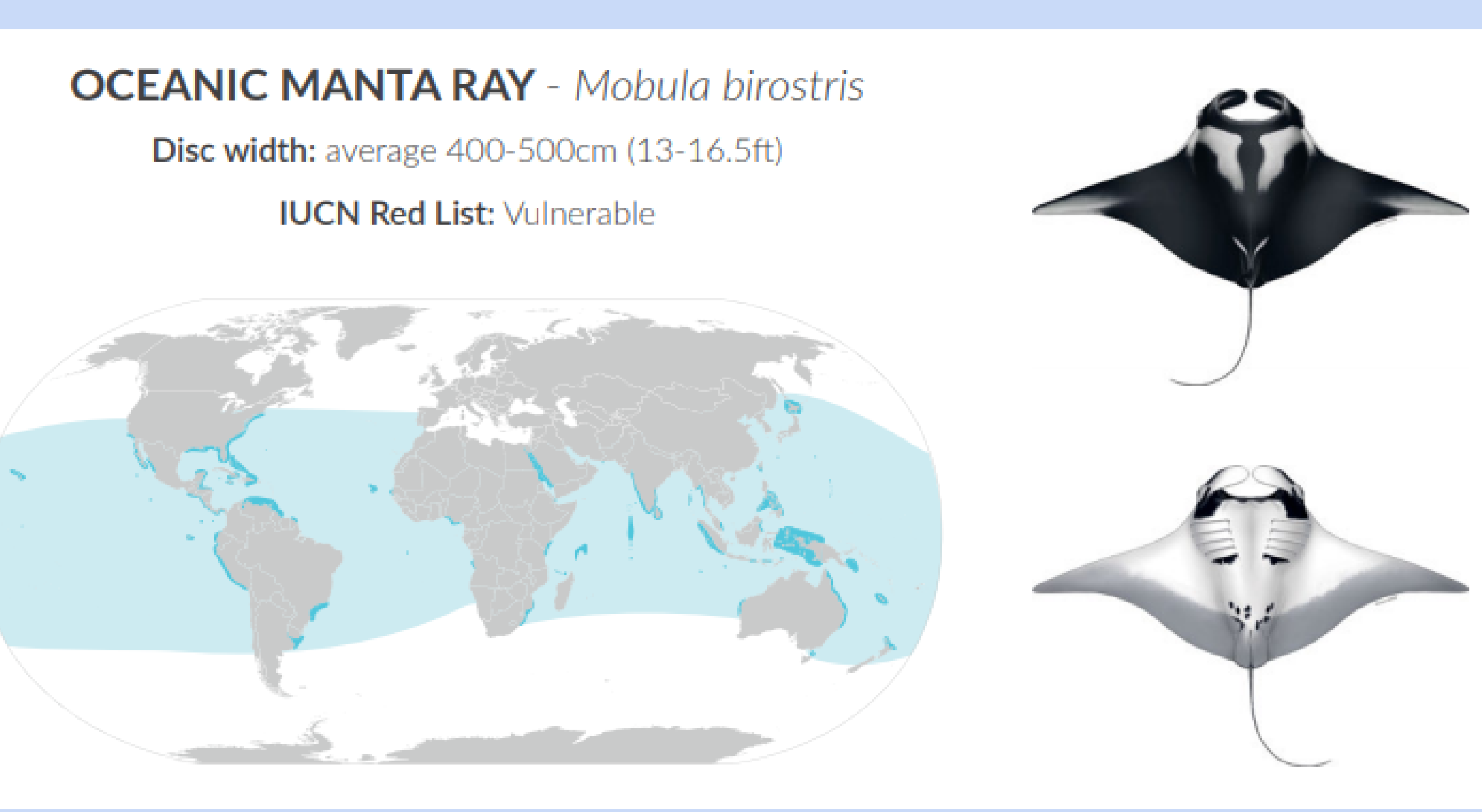

Constant migration has led to a low understanding of their behaviour (Stewart et al., 2016). This strategy is underlined by a three focus approach of: Research, Eco-Tourism and Fishery Regulations.

Figure 2 below, outlines the most prominent direct threats on the species population.

\begin{tabular}{|c|c|c|c|}
\hline PRIORITY & THREAT & GOAL & METRICS \\
\hline 1 & Targeted fishing & $\begin{array}{l}\text { No demand for } \\
\text { mobulid products }\end{array}$ & $\begin{array}{l}\text { Volume of landings; gill plates (in markets); } \\
\text { other body parts (in marketss. }\end{array}$ \\
\hline 2 & Bycatch & Limited bycatch & $\begin{array}{l}\text { Levels of catch \& release; mitigation } \\
\text { measures in gear (gear, spatial, temporal); } \\
\text { policies. }\end{array}$ \\
\hline 3 & Tourism & $\begin{array}{l}\text { Well-managed } \\
\text { tourism }\end{array}$ & $\begin{array}{l}\text { Boat strikes; in-water interactions; code of } \\
\text { conduct. }\end{array}$ \\
\hline
\end{tabular}

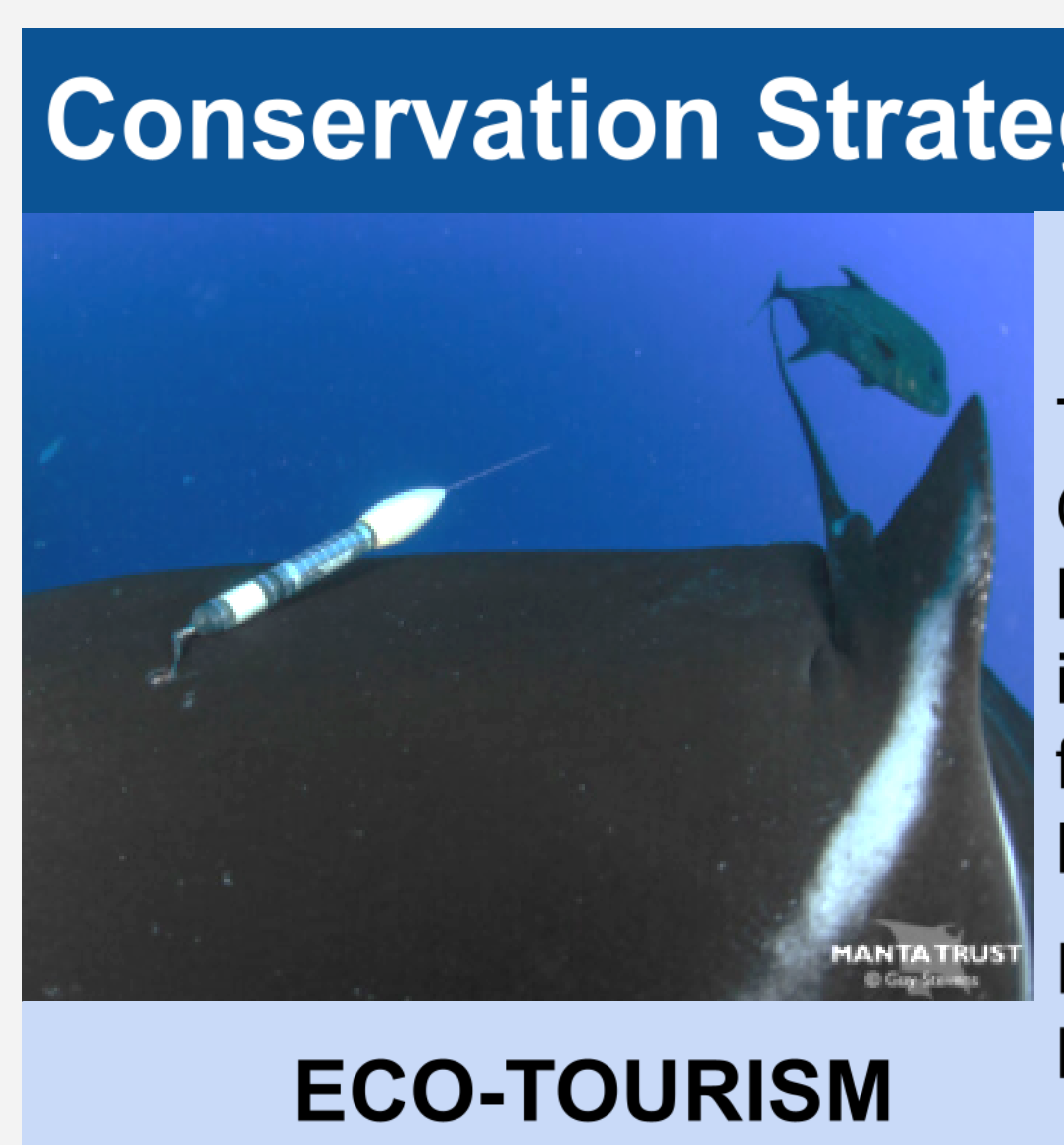

Global Manta Ray tourism is worth $\$ 100$ million dollars as an industry with room for growth (Ender et al., 2020). Also, $90 \%$ of tourists said they preferred sustainable coastal tourism focused on aquatic megafauna experiences (Kessel et al., 2017).

Developing Reefs and tourist/ ray hotspots into protected areas will positively impact ray populations and promote sustainable tourism (Shannon et al., 2018).

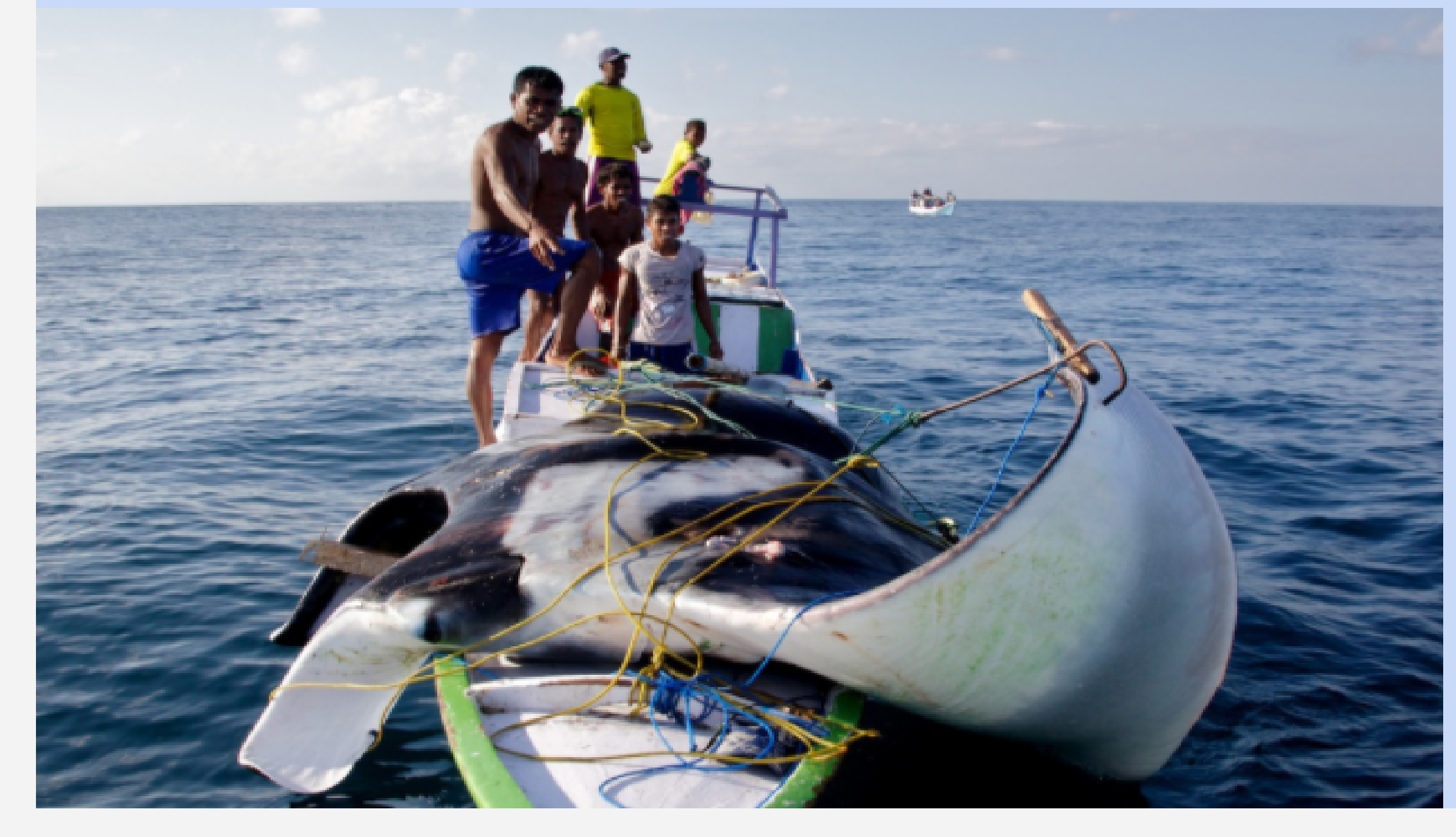

\section{Overview}

RESEARCH

The strategy will be underlined by producing data on Oceanic Manta Ray movements bolstering knowledge of their migratory patterns. This will identify regions/ times of year Rays are most at risk from their main threats: targeted fishing and Bycatch.

Figure 3, left, shows a satellite tag used to track Manta Ray movements (Manta Trust, 2020).

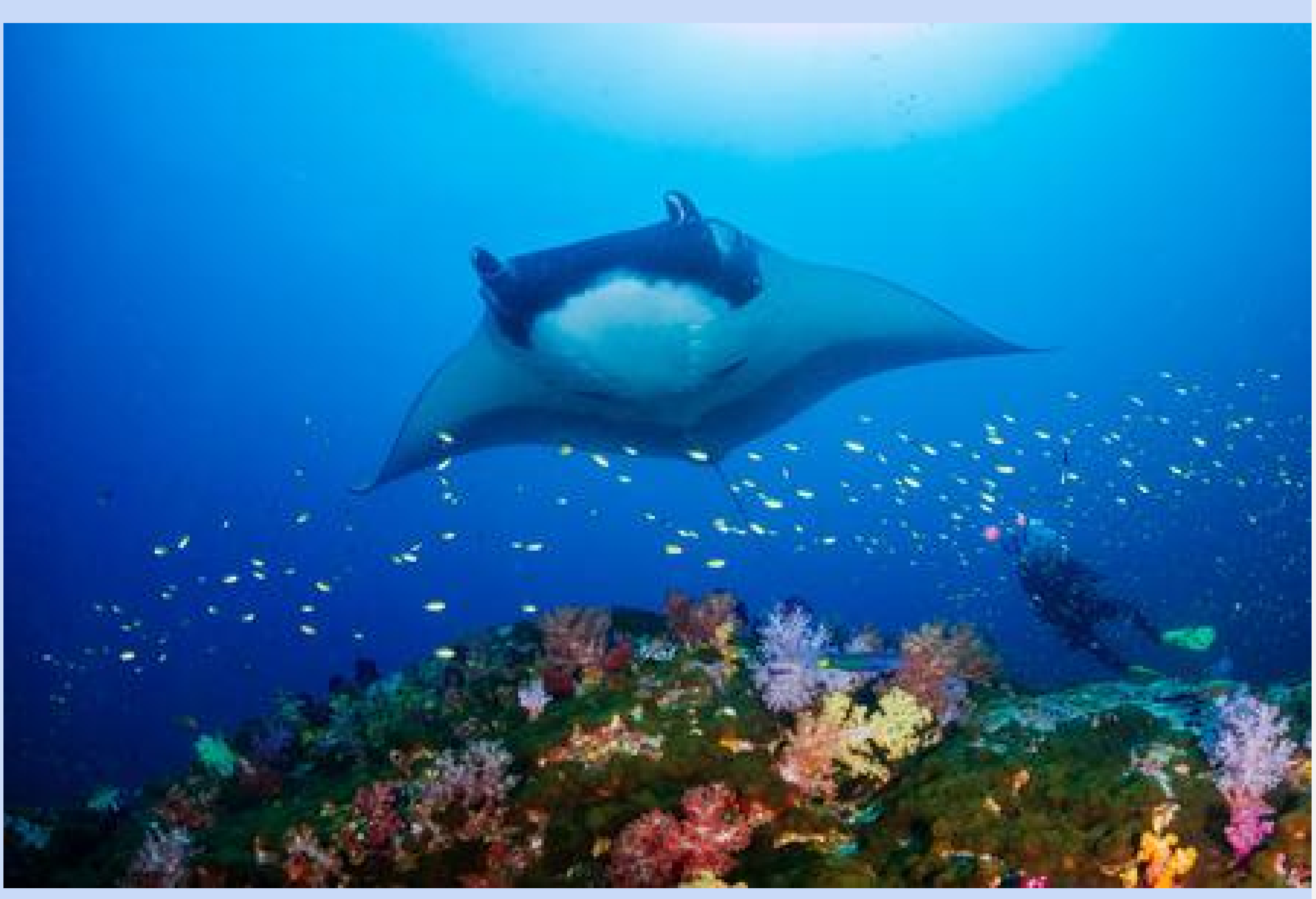

\section{FISHERY REGULATIONS}

Manta Ray Fisheries and Bycatch are the two biggest threats to Oceanic Manta (Ender et al., 2020).

Protecting areas of high Manta productivity through 'Manta Sanctuaries' as Indonesia

has done for a 6 million square $\mathrm{Km}$ area

will rapidly decrease impacts of fishing on

Oceanic Manta Rays (National Geographic, 2020)

\section{Conclusion}

In conclusion, this conservation strategy will help proliferate higher and more stable Oceanic Manta Ray populations via a 3 method approach implementing research, ecotourism and fishery regulations.

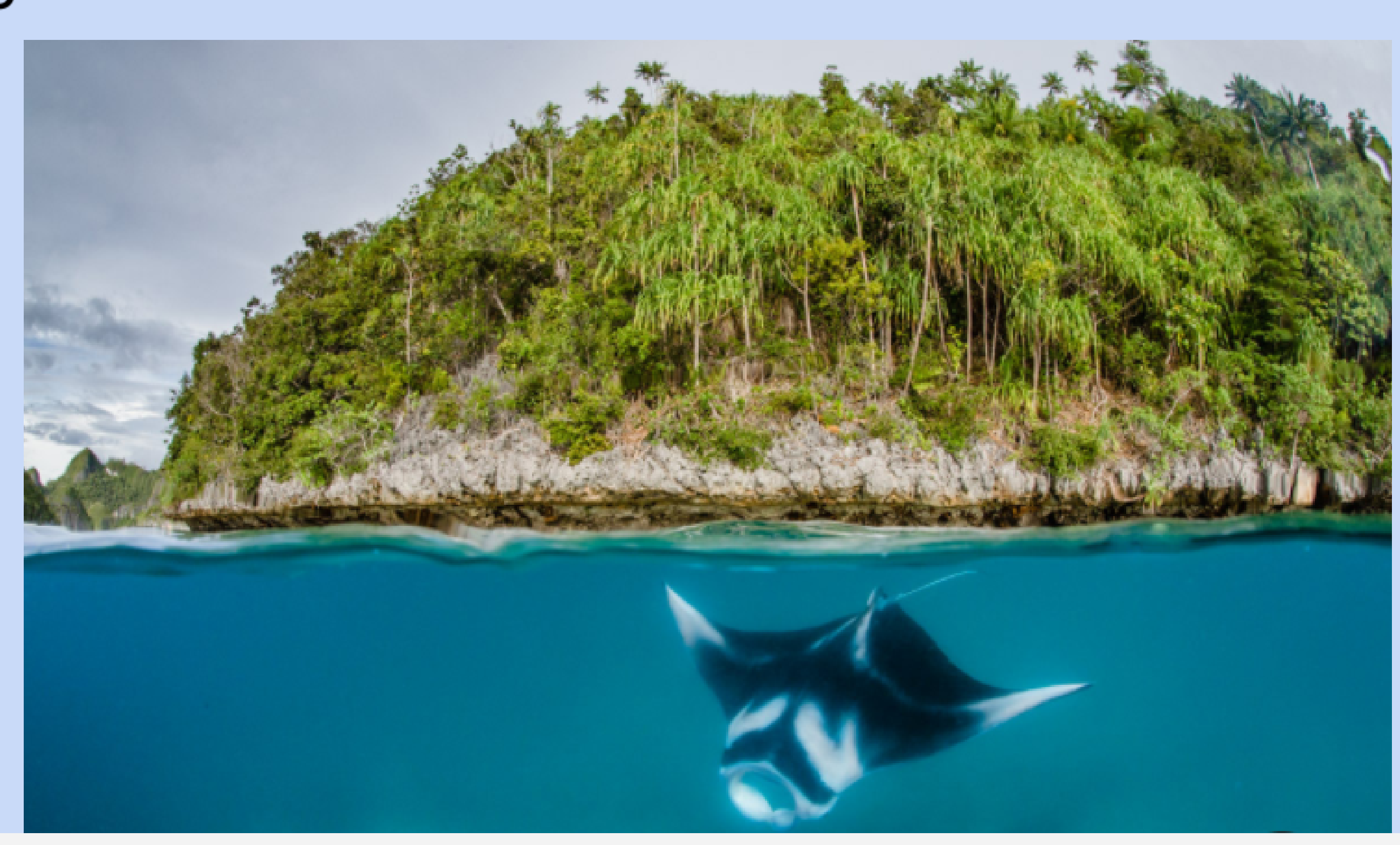

\section{Reference List}

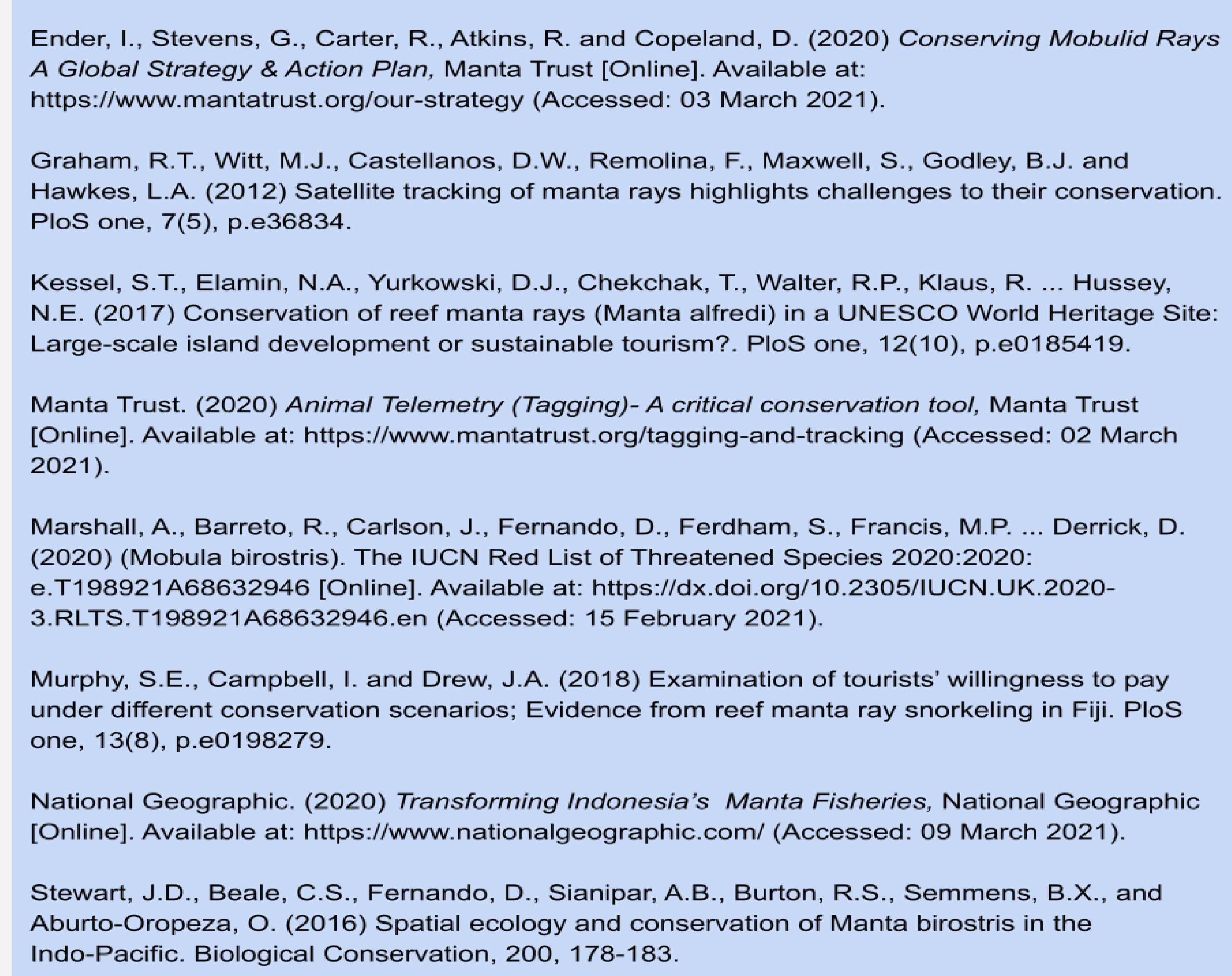

